\title{
Organizational Members' Enactment of Organizational Environments and Media Use: A Study of ICT Practices in Norway and the United States
}

\author{
Alf Steinar Saetre \\ Norwegian University of Science and \\ Technology, Trondheim, Norway \\ alfs@iot.ntnu.no \\ Larry Davis Browning \\ The University of Texas at Austin \\ Austin, TX, USA \\ keriste@mail.utexas.edu
}

\author{
Jan-Oddvar Soernes \\ Bodø University, Bodø, Norway
}

Jan.Oddvar.Soernes@hibo.no

Keri K. Stephens

The University of Texas at Austin, Austin, TX, USA

keriste@mail.utexas.edu

\begin{abstract}
This paper uses the concept of scripts to couple Weick's notion of enactment and Langer's theory of mindfulness/mindlessness with empirical data on the use of ICTs in organizations. Our research is based on 72 in-depth interviews of advanced ICT users in the United States and in Norway. The findings: (1) show that the notion of clear-cut boundaries between an organization and its "environment" is problematic, and illustrate how organizational members indeed enact—or co-create—the environments of their organizations; (2) validate the assertion that mindfulness is required for media richness theory to be predictive; and (3) illustrate how organizational members construct the richness of one media through the use of other media. This study not only enriches our understanding of Weick's theories but also has important implications for organizational practice since it expands media richness and social information-processing theories.
\end{abstract}

Keywords : Enactment, Information and Communication Technologies, Scripts, Mindfulness/Mindlessness, Communication Media Richness

\section{Introduction}

This paper extends our understanding of information and communication technology (ICT) practices by interpreting them in light of Weick's (1979) framework of enactment. Enactment is the pivotal element in Weick's perspectives on organizing (1979) and sense-making (1995). In this research we use the notion of scripts (Ashforth \& Fried, 1988; Barley, 1986; Gioia, 1986, Gioia \& Poole, 1984)-as opposed to Weick's (1979) "causal maps"- focusing enactment toward communication behaviors instead of the

Material published as part of these proceedings, either on-line or in print, is copyrighted by Informing Science. Permission to make digital or paper copy of part or all of these works for personal or classroom use is granted without fee provided that the copies are not made or distributed for profit or commercial advantage AND that copies 1) bear this notice in full and 2) give the full citation on the first page. It is permissible to abstract these works so long as credit is given. To copy in all other cases or to republish or to post on a server or to redistribute to lists requires specific permission from the publisher at Publisher@InformingScience.org processes of organizing and sense-making. Using scripts instead of causal maps allows us to link enactment to Langer's $(1978,1989)$ theory of mindfulness/mindlessness. As we will demo nstrate, the integration of enactment, scripts, and mindfulness/mindlessness yields a powerful analytical framework that furthers our understanding of communicative behaviors in organizations. 
Our empirical data stem from 72 in-depth interviews of advanced ICT users from the United States and Norway. The data offer rich examples of the implications ICTs have for social actors who use them in their communicative behaviors. We use rich narrative data on ICT usage in organizations to illustrate how behaviors and communication choices can be understood in light of the integrated conceptual framework.

In the conceptual framework section we present the concepts of enactment, scripts, and mindfulness/mindlessness. The next section details the qualitative methods used in this study. Following the conceptual treatment and the methods section, we bring our narrative data to life by providing concrete examples that establish the relationship between data and theory. The final section of the paper includes the discussion and conclusion.

\section{Conceptual Framework}

\section{The Role of Enactment in Organizing}

In his book "The Social Psychology of Organizing," Karl Weick $(1969,1979)$ compares the process of organizing to the process of natural selection, and presents a model that consists of the following four elements: ecological change, enactment, selection, and retention. These four elements constitute organizing. Enactment is a concept that captures the role of action in organizing and sense-making. Because all social actors are involved in it, enactment is a crucial process for individuals and organizations alike. Weick (2001, p.187) claims "enactment drives everything else in an organization. How enactment is done is what an organization will know." The same holds true for individuals.

In the following text we give a brief summary of Weick's theory of organizing, showing the centrality of enactment to his theory while relating it to the concept of scripts which is central to understanding Langer's theory of mindfulness. Briefly stated, Weick's $(1969,1979)$ theory of organizing is as follows:

- Ecological change is an alteration in the flow of experience of social actors. These alterations or differences provide opportunities for social actors to make sense of them, to reduce ambiguity. As research on cognition shows, these exceptions are the items that ind ividuals tend to monitor to register change (Einhorn \& Hogarth, 1986). "Ecological changes provide the enactable environment, the raw materials for sense-making" (Weick, 1979, p. 130).

- Enactment - the next step in the process of organizing is the intersection between the activities of social actors and the ecological or environmental changes. Weick states "enactment is to organizing as variation is to natural selection" (1979, p. 130). This is an apt analogy, in that the activities of social actors take different forms in different contexts. Yet, over time, certain activities seem to prevail at the expense of other activities. For example, if an individual is now spending two hours a day communicating via e-mail on her computer and she was doing none of this fifteen years ago, one form of "natural selection" has taken place. The term "enactment" contains within it actions of both social actors and the environment, and implies a co-creation of activities. What these terms have in common is their focus on change and movement.

- Selection involves some kind of arranging of the enacted experiences to reduce their equivocality. This arranging or structuring can be represented in the form of causal maps, or sequences, built on the enacted, or past, experiences. A causal map is a picture of how a social actor perceives elements to be causally and sequentially related. (Weick, 1995). Over time, certain causal maps gain priority because they reduce equivocality more consistently than do other causal maps, even across different contexts. 


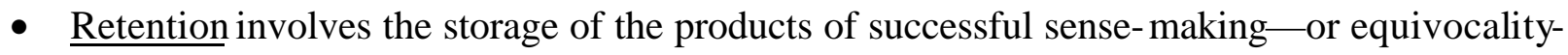
reducing activities. What social actors store are "preferred" causal maps that illustrate how variables are causally and thus sequentially related. Weick uses "the terms enacted environment and cause map to refer to retained content" (Weick, 1979, p.131). It is thus clear that the term "causal map" is fairly broad and encompasses how social actors understand "things" to fit together. Causal maps are thus central to both organizing and sense-making.

It is through the processes of ecological change, enactment, selection, and retention that sense-making and organizing take place. It is, however, important to note that the se alterations - or enactable environments - frequently arise in connection with some action on the part of the social actor. The central premise of the enactment perspective is that social actors create, or enact, the environment that subsequently impinges on their activities (Abolafia \& Kilduff, 1988).

The essence of Weick's $(1969,1979,1995,2001)$ notion of enactment is that people receive input or stimuli as a result of their own actions. When people act, "these actions become the raw materials from which a sense of the situation is eventually built (Weick, 2001, p. 183). Ecological changes-for example, the invention of new ICTs - and people's actions, such as the adoption of new ICTs in the workplace, are both important parts of the raw materials for enactment. Mary Parker Follett pointed to the difficulty in drawing distinctions between environments (stimulus) and actors (response) almost 80 years ago:

What physiology and psychology now teach us is that part of the nature of response is the change it makes in the activity which caused so-to-speak the response, that is, we shall never catch the stimulus stimulating or the response responding (Follett, 1924, p. 60).

The point that Follet (1924) and later Weick $(1969,1979,1995,2001)$ make is that it is very difficult, at best, to distinguish between actors and their environments. This is also the case when individuals relate to one another face-to-face; it is difficult to separate senders (stimulators) and receivers (respondents) because we are continually senders and receivers (Wenberg \& Wilmot, 1973).

When we use the term "enacted environment" we do not mean "perceived environments," as perception is only one small part of enactment (Sutcliffe, 2001). An enacted environment implies an environment of which social actors can make sense and which has been put there by these actors' own patterns of action, not by a process of perceiving the environment (Smircich \& Stubbard, 1985). Weick (1988) points out that enactment occurs through a process that involves both attention (perception) and action. Today, organizational members increasingly use ICTs to be attentive to their environments.

The capacity for the actor to both create the environment through action as well as respond to it is central to our understanding of how individuals enact their work environment through the use of ICTs. Using ICTs to interact with the environment is one thing, but using ICT's is in itself a process of enactment. Orlikowski (2000) states this clearly:

Use of technology is not a choice among a closed set of predefined possibilities, but a situated and recursive process of constitution, which—while it may often invoke intended activities or replicate familiar uses - may also and at any given time ignore such conventional uses or invent new ones (p. 409).

The structures of use of technologies such as ICT are not embedded in the technologies the mselves in such a way that they impose themselves on the users. "Rather they are virtual, emerging from people's repeated and situated interaction with particular technologies" (Orlikowski, 2000, p. 407). Social actors can chose to ignore certain features of the technology, or misuse or abuse other features. The use of information and communication technologies is thus a process of enactment. In the following paragraphs we will elaborate on the enactment process of Weick's $(1969,1979)$ model, while more closely relating 
it to a subset of causal maps, namely scripts, linking enactment to Langer's (1989) theory of mindfulness.

\section{Scripts: The Linking Pin Between Enactment and Mindfulness}

Weick uses the broader construct of causal map because his focus is on organizing and sense-making. Causal maps are the product of social actors' enactment and depict how various elements are causally related (Weick, 2001). In this paper we use the more specific concept of "script," since our focus is on behavior and practices. A script can be viewed as a causal map that is used as a recipe for behavior (Ashforth \& Fried, 1988). Stephen Barley views scripts as "behavioral grammars that inform a setting's everyday action" (1986, p. 83). The term "grammar" here implies a certain sequence of behavior. Gioia and Poole elaborate on the importance of sequences in scripts through their definition of a script as "a schematic knowledge structure held in memory that specifies behavior or event sequences that are appropriate for specific situations" (Gioia \& Poole, 1984, p. 449). Ashforth and Fried (1988, p.306) maintain that a "script is a cognitive structure that specifies a typical sequence of occurrences in a given situation." Therefore, sense-making — the enactment of meaning-is the process of making sense of experiences by tracking the sequence of events. These writers' conceptualizations of scripts validate our assertion of scripts as a subset of causal maps. Given our focus on specific communication beha viors, scripts are more useful than causal maps.

Over time certain scripts perform more consistently than others, even across different contexts, so the y come to be preferred. Individuals' reports of ICT and communication media practices are examples of scripts in this research. The prevalence of certain scripts over others is at the very core of selection and retention. In summary, social actors and organizations can operate as co-creators of their own context and environment. As we strive to make sense of our environment and reduce uncertainty and ambiguity, we are, in effect, enacting context and creating meaning. Weick clearly sees enactment as the essence of sense-making, stating that "sense- making is about the ways people generate what they interpret" (1995, p.13). His statement makes the connection between sense-making and enactment very clear. However, our primary interest here is not in sense-making but in the enactment of causal maps that guide behavior, or scripts.

The invocation of a script results in behavior that is supposed to be appropriate for the situation. Scripts are created as a shortcut, allowing the person using the script to take action based on only a limited part of the available information. Therefore, using a script reduces the person's level of awareness or mindfulness in any given context (Gioia \& Poole, 1984). It is to the issue of conscious or unconscious processing, or mindfulness or mindlessness, that we now turn.

\section{Mindfulness and Mindlessness}

Mindfulness can best be understood as "the process of drawing novel distinctions" (Langer \& Moldoveanu, 2000, p.1). People who are mindful of what they are doing often behave quite differently from those who find themselves acting mindlessly (Langer, 1978). Mindfulness and mindlessness can be viewed as the anchor points on a continuum in that it is possible to locate most communication behaviors within such a framework.

Mindlessness occurs when social actors respond based on only a select number of general cues and ignore other more specific, contextual cues that might suggest a new course of action (Langer, 1978). More recently the definition of mindlessness has been modified and restated as "limited information processing, rigid categorical thinking, single perspectives, and failure to recognize context" (Burgoon \& Langer, 1996, p. 107). That definition fits well with the purposes of this study. 
Repetition and familiar situations move us in the direction of mindlessness, yet people learn through repetition. The problem is that "[u]pon each repetition, less information is processed. Thus, those actions guided by these cues are based eventually only on minimal information" (Langer, 1978, p. 36). The creation of meaning, sense-making, learning, and "the drawing of novel distinctions" are mindful behaviors, but "[o]nce distinctions are created, they take on a life of their own. ... The categories we make gather momentum and are very hard to overthrow" (Langer, 1989, p.11). Thus we have moved from the mindful enactment of categories and scripts to the mindless invocation of them. The initiation of scripts is therefore mindless behavior (Langer \& Moldoveanu, 2000; Langer, 1989). "We build our own and our shared realities and then we become victims of them-blind to the fact that they are constructs, ideas" (Langer, 1989, p.11). When people are mindless, they "treat information as if it were contextfree-true regardless of circumstances" (Langer 1989, p.3). A collective form of mindlessness occurs when a group of people — such as a department, an organization, or even a nation state - treats the norms and morality of its "culture" as if they were the laws of nature.

Burgoon and Langer explain that mindlessness "should be more common when situations are familiar and un-involving, when little effort is required, when consequences are similar to previous ones, and when behavioral routines are not disrupted" (1996, p. 110). Social actors have limited communication and channel capacities for processing information (Broadbent, 1958; Shannon \& Weaver, 1949), and because of this, people process information selectively, causing them to also selectively ignore information (Langer, 1978, 1989). When we invoke a script based on the recognition and subsequent categorization of only a few cues-whether because of familiar situations or limited information capacitypreviously constructed rules and routines are more likely to govern our behavior, irrespective of the presence of novel cues and the current circumstances.

Ashforth and Fried (1988) argue that due to the repetitive nature of many tasks facing organizational members, much organizational behavior occurs quite mindlessly. The communication scholars Burgoon, Berger, and Waldron (2000) assert that much interpersonal communication occurs mindlessly. Repetitive tasks, such as checking one's e-mail and selecting a communication medium for each communicative interaction, are prone to mindless behavior. Timmerman (2002) argues that media-selection theories, such as media richness, and social-influence theories are non-predictive unless one takes into consideration the mindlessness/mindfulness of the actor.

Mindlessness can also be viewed as entrapment by categories (Langer, 1989). That is, we attend to only a limited set— the evoked set (Abougomaah, Schlacter \& Gaidis, 1987)—of available cues while ignoring other potential distinctive cues that would allow us to draw novel distinctions. In the words of Timmerman (2002, p. 114): "Mindlessness is a state in which one does not attend to information in the environment, but rather behaves in an automatic fashion, minimally attentive to behavior." Mindlessness can stem from various factors: (a) overlearned behavior, (b) cognitive commitment, (c) reliance on existing categories, and (d) limited attention paid. It is reasonable to expect that most, if not all, of these factors are present to various degrees whenever mindless behavior occurs.

Figure 1 summarizes the relationship between the variables discussed above.

In most of the writing on mindlessness and mindless behavior there seems to be an implicit assumption of linearity. That is, social actors observe some familiar cues which trigger a script and lead to a specific mindless behavior that is, according to the script, appropriate to the situation. However, it might well be that these cues that social actors observe trigger a set of scripts that in turn focus their attention toward certain types of information (trying to confirm which script is most appropriate) and away from other types of information (what is unique about this situation or event). This explanation seems to fit well with Weick's $(1979,1995,2001)$ notion of retrospective sense-making. 


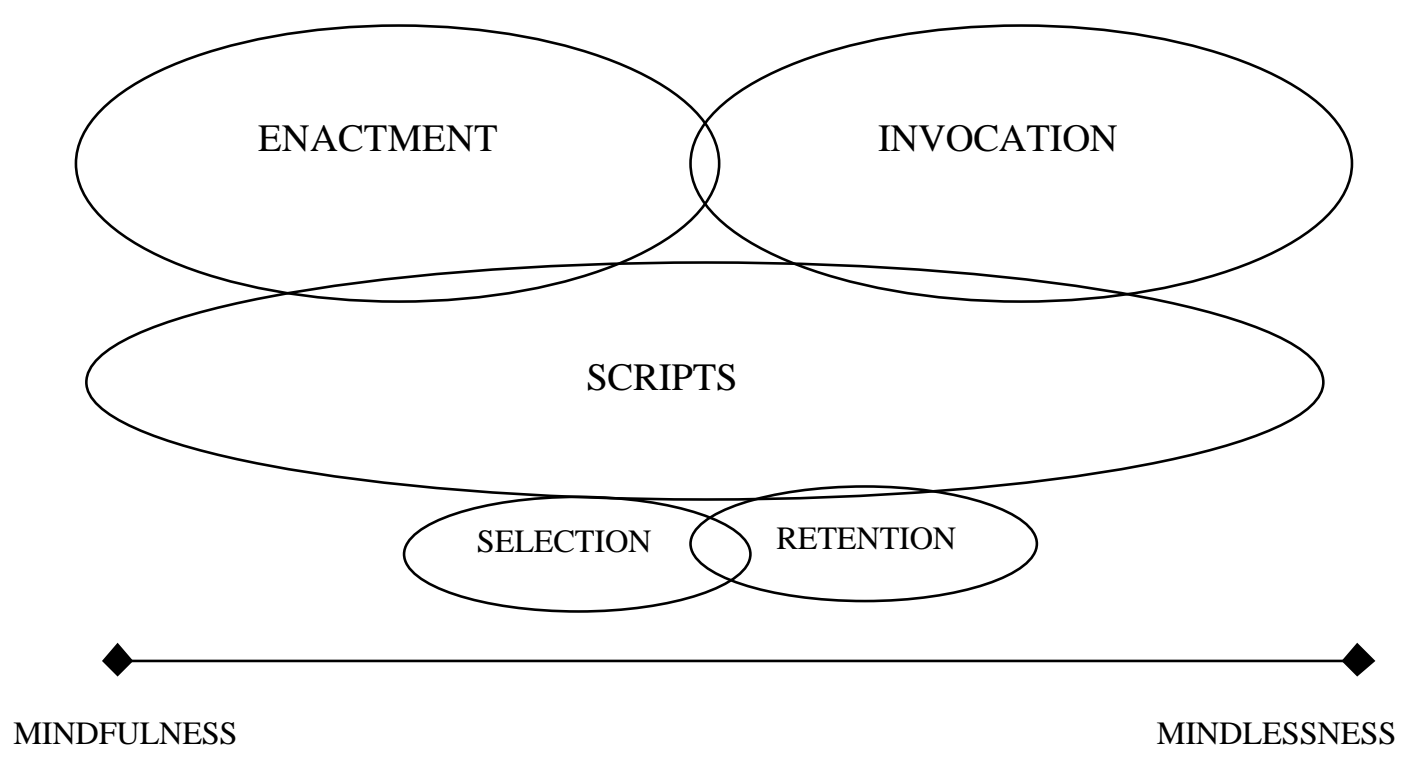

Figure 1. The Relationship Between the Constructs

Before we turn to connecting the concepts of enactment, scripts, and mindlessness/mindfulness to our data set, we will briefly lay out our methodological approach.

\section{Methods}

\section{Data Collection}

The data for this study was collected in a two-stage research effort. Data collection in stage one started in the fall of 2000 and ended in the spring of 2001. Data collection in stage two started in the winter of 2001 and ended in the fall of 2002. A total of 72 individual interviews (36 in Norway and 36 in the US) were conducted by four researchers over the course of these 2 years. The participants were selectively sampled based on their reputation as advanced ICT users. Special effort was placed on identifying ICT users from as wide a range of professions and organizations as possible. Participants consisted of a cross-section of users representing different functional areas, professional and organizational tenure, and gender.

Each interview lasted 45-90 minutes and was audio-recorded. The recordings were then transcribed, resulting in over 2,000 pages of text. To facilitate subsequent data analysis, the Norwegian data set was translated into English and checked for semantic and contextual accuracy by the Norwegian researchers. For analysis, the Norwegian interviews were printed with Norwegian and English translations side-byside. This was done in order to retain the richness and nuances imbedded in the language of any statements/instances that we wanted to examine more closely.

Data was collected using loosely structured, in-depth interviews - a method that is flexible and that favors adaptation to each context and individual (Miles \& Huberman, 1994). Because this research involved multiple sites and multiple interviewers, it was especially important to employ a similar format for the interviews, developing a common framework and maintaining cross-case comparability (Miles and Huberman, 1994). An interview guide was designed for this purpose. The structure of the interview 
guide also permitted the exploitation of opportunities that presented themselves. The interviewer introduced a topic and provided the transition to the next topic when appropriate.

\section{Data Analysis}

The research presented in this paper is part of a larger investigation on ICT use in the workplace in Norway and the United States. In a previous paper, a comprehensive grounded-theory analysis (Glaser $\&$ Strauss, 1986) of the data was reported (Stephens, Browning, Soernes, Schmisseur \& Saetre, 2002). All data was coded by multiple coders, yielding almost 5,000 individual codes, which were subsequently categorized into 59 core categories (for a description, see: Stephens, Browning, Soernes, Schmisseur \& Saetre, 2002). For this study we select vignettes or narratives from the interviews that contain accounts relevant to our proposed conceptual framework. We used the researchers' intimacy with the data, as well as searches of our data base, to select the narratives used for analysis in this paper. We searched separately for examples of the three central theoretical constructs of this paper: enactment, scripts and mindfulness/mindlessness. This is consistent with Glaser's (1978) view that researchers may flexibly draw on and construct frameworks based on the theoretical leads suggested by their data. Similarly, Strauss (1970) admits that while the emphasis in the 1967 monograph with Barney Glaser was theory generation, its analytical style could also be used in the context of previously developed theory — as long as it had been carefully grounded in research.

In our analysis, presented in the following sections, we couple our theoretical framework-as laid out in the previous sections - with the selected narratives from our substantial pool of raw data. The theoretical frameworks served as a sensitizing device for looking at, interpreting, and analyzing the narrative data (Browning \& Henderson, 1988; van den Hoonaard, 1997). The close coupling between the data and the theoretical framework is reflected in the following sections.

\section{Findings: Linking Data and the Conceptual Framework}

Using our integrated theoretical framework for data analysis, we find examples of enactment, scripts, and mindfulness in all 72 of the interviews. Given that the focus of this study was on ICT use, it is not surprising that the data showcase numerous examples of how the individual actors use ICTs as their raw materials and rearrange ICTs to respond to different situations. Since the goal of this study is to contribute a clarifying explanation of how ICTs are used in organizations, we provide the following theoretical clustering of concrete examples. In support of our integrated theoretical framework, our examples will show that the constructs of enactment, scripts, and mindfulness/mindlessness are not just tightly related, they are in fact integrated, and this integration is reflected in our analysis.

\section{Enactment as a Supercategory}

First, we find that enactment functions as a "supercategory" and permeates the data set. It is often through the presence of an external environment that scripts are devised and mindfully or mindlessly executed. This view is shared by many organizational theories that characterize organizations and their external environments as complex systems that constantly interact (Anderson, 1999; Daft \& Lewin, 1990). These complex interactions create new avenues for sense-making. For example, interviewees who are sales representatives discuss how they adjust their own personal ICT-use scripts to accommodate the needs of their customers. Without an external agent driving their script formation or execution, ICT use would be different. Essentially, ICT use does not happen in a vacuum; it is consciously and unconsciously influenced by the environment. These findings suggest that organizational boundaries are often ambiguous and the (enacted) environment is a powerful agent affecting ICT use. 


\section{Mindfulness in Action}

The second major finding suggests that while most script enactment is mindful, it varies. Prior research has indicated that the invocation of scripts can be mindful or mindless (Gioia \& Poole, 1984); but the data presented below suggest that this bifurcation is simplistic. The examples from the data suggest that not only are there different levels of mindfulness in ICT script use, but there are also mindful combinations of ICT use. In these examples, mindful social actors actually consider at least some of the underlying dimensions of media-choice theories - opportunity for fast feedback, ability to convey multiple cues, opportunity to tailor the message to the situation, and ability to convey ambiguous and subjective material-when selecting their communication media.

If we place enactment on a continuum ranging from highly mindful to mindless, we can learn more about ICT use. Toward the high end of the mindfulness continuum is an example of ICT use where successful practices are actually stolen from others and implemented in new organizations. A member of the staff at a Norwegian college told the story of how they went about constructing the web pages for the college, which they did in collaboration with an external web-design firm: "We tried to describe to this little company what we were aiming for. ... In doing this we have stolen shamelessly from all the other solutions on the market." In other words, the environment itself becomes a part of how the organization seeks to present itself to the environment and thus set itself apart from it.

For example, the economy can serve as an ecological change agent and affect the creation of mindful rules with clear objectives. A consultant in the high-tech industry in Silicon Valley explains the impact of the economic downturn on the use ICTs in the following manner: "Well, certainly, in our firm there's a lot less travel, and so there's a lot more emphasis on electronic communications." In this manner the high-tech firm is in fact contributing to the economic downturn that it is "reacting" to. This interview also shows that an enacted environment can cause us to draw new distinctions-e.g. "It is not costefficient to travel to Atlanta, so let's have a video conference"-whereas previously there would have been a meeting in Atlanta. In other words, social actors are more mindful of media usage in this newly enacted economic environment than they were in the previously enacted economic environment.

Several of our informants, on both sides of the Atlantic, were very mindful of their communication partners' media preferences. In fact, some of them were so mindful of their preferences that clients' media preferences become a communication media-selection script. One of our American informants-a salesperson in the high-tech industry-made this explicit:

Some people say, "Send me an e-mail on everything you want to communicate because I'm very disciplined about reading my e-mail." That is fine and that's what I'll do. Other people say, "Page me and I'll always call you back." That is fine too.

Being mindful of the recipient's - in this case, the customer's - media preference ensures timely responses to communication attempts. One of the main reasons that it is important to learn about these preferences is that if a salesperson ignores the customer's media preference, the customer may not communicate with them. Our informant made this clear: "I could leave him three voicemails a day, [and] he never talked to me. Page him and he'll be back to me in 30 seconds."

There are also examples of mindfulness found in other types of customer interactions. A project coordinator at a Norwegian software company, who told us a story of how customer requirements are often enacted, claims, "Some customers have a clear strategy for their learning needs and methods, which we strongly disagree with." What he is saying here is that customers often do not know what they want, and certainly not what is good for them, but his organization does know. "The idea is to educate the customer about e-learning based on the products we sell. ... The idea is to educate our customer before our competitors do." He is mindful that if he can help the customer define the problem, the customer is perhaps more likely to let him help solve it. However, this strategy is not a "carte blanche" for unethical 
behavior. He says, "It does not pay off in the long run for us to sell a product that the customer will not use, or is not able to use." So he is mindful of the longevity of the relationship. Since he knows what is best for the customer, then he thinks that it is his job to enact the customer requirements that his company is facing.

\section{Importance of Face-To-Face in Mindful ICT Use}

The most prominent mindful ICT theme in the data concerns the importance of face-to-face communication in important or what is perceived to be emotional situations. One US salesperson explained, "If a customer has any sort of emotion, if it's a subject that's emotional, whether positive or negative, I'll go see him, because in sales every decision is emotional." This person is mindful of the power of the "faceto-face to close deals" script, because he sees every closing or decision as emotional, and emotions can best be dealt with through rich communication channels, or media, such as face-to-face. His mindful use of rich media for ambiguous or emotional situations fits well with Daft and Lengel's Media Richness Theory $(1984,1986)$. He is also enacting his own work context by setting client expectations through his media choices. If he switches to a leaner medium, such as e-mail, then the switch will convey a message in itself (Sitkin, Sutcliffe \& Barrios-Choplin, 1992).

One of our Norwegian respondents offered some additional insights into an expanded version of the same script. This person was a sales and marketing director for an IT firm offering "real time" solutions. Over $70 \%$ of his contact with customers was by e-mail. Nevertheless, he pointed out that the most important part of the customer relationship takes place face-to-face. "Face-to-face is a must in the initial stages, throughout the process to resolve conflicts or disagreement, and in the closing of a sale." Not only does he include the deal-closing scripts, but he also extends the script to include using face-toface for initiating relationships. But he is also acutely aware-mindful-of why face-to-face is so useful in the closing of a deal, and it is very simple, really: "E-mail is not suited to deal with conflicts, because it to rigid." So his mention of the flexibility of a particular medium is still another formulation or reason for choosing a medium.

The next example provides some insight into how this face-to-face script is enacted. An American interviewee who conducted a fair amount of international business stated: "For a decision of that size I think, in almost every case, there's got to be at least one or two face-to-face meetings." This person also had a colleague who worked internationally and who had concluded that in closing such deals, face-toface communication was required: "It's rare that a deal gets concluded without face-to-face." The following US example from a person who conducted most of his business domestically makes a similar point:

If you're going to spend that kind of money, they're going to want to meet our sales people, our sales managers, our vice-president, our executives. The bigger the deal, the more face-to-face time it requires. ... In our industry there's a lot of CEOs who spend half their time just closing deals.

The Norwegian interviewee recognized a "face-to-face for closing deals" script, whereas the US interviewee was very aware of this as well as of the ubiquity of this script within the industry. That is, he was mindful of the presence of this enacted script. To the extent that social actors are mindful of the ambiguity of given situations - such as initiating a relationship, or closing a deal-they are selecting media in accordance with the predictions of Media Richness Theory (Daft \& Lengel, 1984, 1986).

\section{The Mindful Enactment and Mindless Invocation of Scripts}

Thus far we have focused on findings that illustrate mindful enactment of ICT-use scripts. But there is a much wider range of mindfulness_-including the possibility of mindless use. While we as researchers 
acknowledge that mindlessness is difficult to observe in interviews where beha viors are self-reported, through examples we can provide plausible evidence that routines are established and result in ICT use that happens without much consideration. Due to retrospective sense-making, it is reasonable to expect that interviewees will retrospectively make sense of even their mindless behavior (Weick, 1995). The degrees of mindlessness also vary. Some behavior results from a script that was originally mindfully enacted. Other behaviors appear to be partially mindful in some aspect, yet are mindless with regard to other important areas.

One of our American interviewees had a very clear script for how to search for information: "So I probably use Google very systematically 20 times a day. And anything that I want to know about I'll do a Google search." The latter part of her statement makes it clear that this is, in her mind, a reliable method or script for finding information, one that she invokes every time she needs to know about something. Although being mindless when invoking this Google script, she was mindful when she created it:

What Google does-other engines will return a result as a function of how frequently a certain term is used on that Web site. Google looks at how many times a Web site is accessed that has those terms. So you always come up with the most used sites, which are usually the most useful sites. ... And the real power, I think, from Google is that you have implicitly built into it the wisdom of hundreds of millions of people, right?

Not everyone places such great confidence in the collective intelligence of people, as Thornton Wilder stated: "Ninety- nine percent of the people in the world are fools and the rest of us are in great danger of contagion" (1954, The Matchmaker, Act I.). She is, however, mindful of why she constructed her own search script. Nevertheless, we can see the seeds of her subsequent switch to mindlessness from her mindfulness. Her Google script seems to embrace the notion that if Google can't find it, it doesn't exist-which in turn is the same as: if many people have not found if before me, it doesn't exist. She is clearly mindless of this aspect of her script, since being a consultant often is about providing the organization with new information; that is what others have not found before her.

While the resulting mindless use of Google might well have been a good overall decision, some scripts result from mindless behaviors based on less rational reasons. A continued education (executive education) counselor at a Norwegian University told of how he and his colleagues used various media. With colleagues in the same building, a combination of face-to-face and electronic media was used. But some of his colleagues were located in the next building over- "it is not far, but almost all of their discussions and communication happens through e-mail." Our informant and his colleagues clearly had a script that if they needed to communicate with people in the other building, then they would use electronic media because it was too far to walk, and whenever the need for communication with these colleagues arose, then they paid less attention to the content and purpose of the communication than to the physical distance. While this example illustrates a certain degree of mindfulness in their choice of e-mail, it also illustrates a certain level of mindless script invocation. This selective cuing supports the notion that there are levels of mindfulness to be found in ICT use. In other words, he attended to only a few of the available cues (distance), and ignored other and perhaps more important cues (content, context and purpose of the communication). Not being mindful of the communication task characteristics-such as equivocality—leads him to choose the same lean medium—e-mail—when other, richer media, such as face-to-face, would have been more appropriate and more effective.

The US salesperson who viewed decisions as emotional placed a high premium on face-to-face communication:

My philosophy is very simple: If I have an opportunity to meet with a customer, I will drop everything else-because it's more important. And even if I spend two hours and only get five minutes' worth of information, I never would have gotten it if I didn't see them. 
He went on to say that he might do quick questions on voice mail, or even send an e-mail "if it is unimportant," but if he thinks the information has "any significance" he will definitely use face-to-face. He clearly does not believe that leaner media are complementary to rich face-to-face communication, but that leaner media are only for insignificant and unimportant short messages. This script—-the superiority of face-to-face communication at all times-leads him to spend 120 minutes on getting something that should have taken 5 minutes, and to his finding the extra time and effort spent to be rational and worthwhile. Although he thinks he is mindful (I do this because everything is emotional, and emotions can only be dealt with face-to-face) he is in fact mindless (he does not attend to any of the cues that might lead him to use leaner media, such as receiver preference, convenience, speed, availability of media, and so forth) when invoking this script that leads him to utilize an inappropriate medium, at least according to media-choice theories (Daft \& Lengel, 1984, 1986; Fulk, Steinfield, Schmitz \& Power, 1987; Sitkin, Sutcliffe \& Barrios-Choplin, 1992). The initiative to act face-to-face, even though it is a significant allocation of resources, is less mindful than routinely considering several variables.

\section{Consequences of Mindful ICT Use}

Some mindful script invocations begin with one objective and result in novel unintended consequences that are either desirable or not. A management/IT consultant acquired a broadband Internet connection to enhance her productivity when working out of her home. As a result of this ICT implementation, she had more desirable family interactions, and she expanded the ICTs used to communicate with others in her organization:

A lot of it is driven by kids, and when you have broadband you don't have to tell the kids to get off. And when you have broadband it's easier to share a connection, and so, you know, people start accumulating computers like at one time they started accumulating televisions. So there are more people communicating.

In the following example we see that the mindful use of Microsoft Outlook facilitated informationsharing during vacations. A section leader at a US historical center said:

I'm such a dictatorial person-and my boss is too- that everyone is required to have the same scheme on their computer. The rationale behind this requirement for similarity was quite simple. We have to pinch-hit for each other so frequently. And we do want to take vacations. So we try to keep things organized so we can fill in for each other. And so if I'm ans wering an e-mail reference, I answer it and then I file it in a certain spot. And then the next person who comes on for the next shift knows exactly where I was supposed to put it.

To achieve this common structure they simply used folders in Microsoft Outlook. So enactment can be merely establishing a common standard rather than a unique and personal practice.

In addition to these desirable consequences, we also see examples where mindful ICT use creates new problems. A Norwegian college professor was using technology to impose a specific learning experience on students. He deliberately reduced the functionality of a previously used software application so that the students had to use a new software package to complete some of the assignments. This mindful creation of a learning environment had some unforeseen consequences. He discovered that the word traveled fast about his requirements and students monitored whether others were being required to do the same thing, and students "started to question why others did not do it." The professor monitored these misgivings and noted the mounting pressure on his colleagues to do the same, which placed him "ahead of the game." In this example, the professor thought he was creating - mindfully enacting-an environment for his students to learn, but he also affected the working climate for the faculty in his department and at the university at large, by setting the expectations of students - an unintended consequence. 
Another example of unintended consequence is provided by one of the IT firms in Norway that attempted to create an exchange relationship with its employees. The firm provided employees with a cell phone, but in exchange, the firm had the right to contact employees at all times to seek information or request help in solving company problems. As our interviewee said, the firm "had a "crystalclear policy that when the cell phone is on, we can call them anytime day or night." He offered, as an example, the firm's running into problems with software code. If such a moment occurred, they would "call the number, and if the cell phone in on, which it often is if you use the number for all your friends as well, then we reach the person." The motivation for this policy was quite clear, as was the incentive for programmers to leave the cell-phone on.

But this policy, and the employee's exploitation of it, created an enacted environment that almost eradicated the distinction between company time and private time. It led to the problem that a person was never really off work. Our interviewee, one of the three founders of this company and an institutor of this cell-phone policy, solved the problem thus: "So I often turn the phone off for a whole day, to people's great irritation. It is one way of doing it - so people can choose between cheap phone and at the same time be called." In this case the cell-phone policy might have contributed to employees using ICTs — such as chat (ICQ and Messenger), text messaging (SMS), and the phone — to bring their social lives to work. This example shows that there are stages to enactment. The leaders might be mindful of what is intended by a certain behavior, in this case a cell-phone policy, but they were unable to see the eventual consequences of the policy.

Our next example comes from a Norwegian couple, owners of a dairy and pig farm, who had invested heavily in farming technologies and also ICTs in order to increase the efficiency of their farm. Their investments had led to a new kind of problem: "We can't call the relief worker-ring just to say that now we want a relief worker. That doesn't work for us-there is too much technology in our cowshed for doing that." The new farming environment that they had enacted through their investments in hightech placed a new "environmental" problem in that relief workers with the right set of competencies were hard to find. In this case, enactment that generated one kind of opportunity also unintentionally restricted other options, such as taking vacations, as opposed to what occurred at the US Historical center, where enacted ICT usage actually enabled members to take vacations without work being interrupted.

A Norwegian professor gave us an example of being more or less mindful when writing e-mails: "When I communicate with colleagues, then I am more thoughtful on what I am actually writing. ... They also require a more thought-out answer. ... I feel that with the students I can be a bit more lax." He is mindful of who the receivers of his e-mails are, and adjusts his communicative efforts accordingly. Once he sees who the receiver is, he pays little attention—is not mindful— to the content and purpose of the email. He has a script for how much writing effort to put into his e-mails based on who the receiver is.

Furthermore, this professor is in fact creating an important part of his own working environment, since both colleagues and students are important parts of his work day, and how they view him and interact with him are largely based on their perception of him. The way he communicates with people-students and colleagues alike-influences how they perceive him and thus how they interact with him, which is an important part of his working environment. Although he is mindful of his communicative efforts, he may not be aware - unmindful — of the enacted environment or work context that his mindful behavior creates.

\section{The Enactment of Media Richness Through the use of Another Media}

While many interviewees have mindful preferences for one ICT over another, they also explain another unintended consequence of mindful ICT use: how one ICT choice affects a different ICT. One Norwegian executive education counselor explains that when there is no relationship established, he is mindful 
of how he crafts e-mail messages: "I do relate more formally to this person [someone new] in written form, and I am more careful then ... because I will spend time on formulating myself in a good way." As the actors interact, they enact or co-create a relationship that consist of trust and to various degrees, mutual understanding:

What I say is that it is easier-for example, some project managers that I been working with for 3-4 years now, and they know me very well, in a way ... and I am much more effective towards them than I am towards others. This enacted relationship facilitates communication. In a sense, social actors enact—through the use of interaction and multiple media - the richness of leaner media, such as e-mail: I know some people very well because I have met them physically on many occasions ... because we have established a relationship-a working relationship, but I do feel that the use of the net [e-mail] is much easier now when I know the people from the physical meetings. I can write them in another way.

In this case, the use of one medium-face-to-face-affects the perceived and experienced richness of another-e-mail. In other words, the richness of a particular medium — in this case, e-mail—is not only a function of the objective media characteristics — media richness theory (Daft \& Lengel, 1984 1986) or the collective perception in a group of that media—social information processing (Fulk, Steinfield, Schmitz \& Power, 1987) - but it is also a function of how the richness of that medium has been enacted among the communication participants on previous encounters and through the use of other media.

The use of rich media, such as face-to-face communication, to increase the richness of leaner media can also be seen in the following example from an American salesperson, who offered some additional insight into the enactment of the previously described "rich media for closing deals" script: "I will spend a lot more personal time with somebody I don't know. I will very rarely page a new customer." He does not feel that it is appropriate to use leaner media until a relation is established: "I will very rarely send them e-mails until I get to know them." His reason for this was that before he could use leaner media such as e-mail and pagers he needed to "build confidence and trust with that individual." Once he had done that, then "it's acceptable to send them pages, send voicemails, or e-mails. But I try to keep that to a minimum until I really feel comfortable with them as well as they feel comfortable with me." Through the use of face-to-face communication he establishes a relationship that allows him to subsequently use leaner media in the relation; he enacts the richness of the leaner media through the use of richer media.

Face-to-face communication is considered appropriate for dealing with emotion and conflict since the ability to pick up on multiple - and perhaps conflicting — cues, as well as allowing for flexible communication and immediate feedback is essential (Daft \& Lengel, 1984, 1986; Lengel \& Daft, 1988; Rice, 1993). For these processes_-initiating relationships, and closing deals-face-to-face communication is preferred by several of our informants both in the US and in Norway. They prefer rich media for these tasks because of the ability of rich media to deal with multiple cues and to be flexible, but also due to a (perceived) need for immediate feedback. In both the initial stages of a relationship and when closing deals, uncertainty and ambiguity are high, and richer media are therefore considered more appropriate (Daft \& Lengel, 1984,1986). Our findings of the mindful use of rich media in situations of high ambiguity, and in augmenting the richness of leaner media, lend partial support to Timmerman's (2002) claim that it is when social actors are mindful that media choice theories (Daft \& Lengel, 1984, 1986; Fulk, Steinfield, Schmitz \& Power, 1987; Sitkin, Sutcliffe \& Barrios-Choplin, 1992) are predictive. In these examples, mindful social actors actually consider at least some of the underlying dimensions of media-choice theories-opportunity for fast feedback, ability to convey multiple cues, opportunity to tailor the message to the situation, and ability to convey ambiguous and subjective material—when selecting their communication media. 


\section{Conclusions}

This study suggests that the constructs of enactment, scripts, and mindfulness/mindlessness are not just tightly related, they are in fact integrated, and can be used together to better understand the use of information and communication technologies. The findings support the view that ICT-use scripts are often co-created between individuals and their environments. These scripts are often enacted mindfully; however, mindfulness occurs on a continuum and is influenced by a number of factors. The most common mindfully enacted script is that face-to-face communication is used for emotional or ambiguous and important situations. Scripts can also be mindfully created, yet mindlessly invoked and used even when they might be ineffective. Mindful ICT use can also have positive and negative unintended consequences. Finally, varying levels of mindful ICT use can affect perceptions and use of additional ICTs.

While this study serves to integrate Weick's theory of enactment and Langer's theory of mindfulness, several opportunities for future research exist. Prior research has theorized the concept, and while this study drew implications from data, actually measuring mindless behavior remains a challenge. Interview data relies on self-reports of behaviors, which means that interviewees are enga ged in retrospective sense-making of mindless behavior when giving accounts of behaviors, mindless and otherwise.

Another area for future research is in the exploration of unintended consequences of mindful ICT use. The findings of this paper validate the prevalence of unintended consequences of mindful behavior; however, we know very little about how these unexpected outcomes affect behaviors and ICT use. For example, if highly mindful ICT use results in something unexpected, does that result in the mindful modification of scripts? The answer from studies of disaster is that we do learn from mistakes and unintended outcomes (Weick \& Sutcliffe, 2001). As our findings ind icate, mindfulness/mindlessness is not a dichotomous variable, but a continuous one. Is, then, the degree of "unintendedness" really just a reflection of the level of mindfulness? Since, as we have shown in this paper, social actors are more or less mindful, and enactment is something that occurs when we are relating to our environments-as social creatures this is something we do constantly - then a fair amount of our enacting our environments should occur in a state of relative mindlessness. Exploring the implications and scope of mindless enactment should prove a ripe field for future research.

The findings of this study lend both positive support, and negative support to Timmerman's (2002) claim that it is when social actors are mindful that media choice theories (Daft \& Lengel, 1984, 1986; Fulk, Steinfield, Schmitz \& Power, 1987; Sitkin, Sutcliffe \& Barrios-Choplin, 1992) are predictive. Positive support stems from the finding that when social actors are mindful of the communication tasks at hand they choose appropriate media, and negative support from the finding that when social actors are not mindful of the communication tasks at hand they choose inappropriate media. However, the evidence provided here is limited in scope, and this issue provides an interesting venue for future research.

The complexity of ICT use is not likely to decrease in the near future. Regularly we find that new ICTs emerge through technology advancement and by combining existing ICTs. As ind ividuals make sense of ICTs, they will continue constructing, using, and modifying scripts. As scholars, it is our task to study the scripts, create models of use, and empirically test the models. It is through our theoretical contributions that we develop sustainable explanations for behavior.

\section{References}

Abolafia, M. Y., \& Kilduff. (1988). Enacting market cris is: The social construction of a speculative bubble. Administrative Science Quarterly, 33, 177-193.

Abougomaah, N. H., Schlacter, J. L., \& Gaidis, W. (1987). Elimination and choice phases in evoked set formation. The Journal of Consumer Marketing, 4(4), 67-73.

Anderson, P. (1999). Complexity theory and organization science. Organization Science, 10, pp $216-232$. 
Ashforth, B. E., \& Fried, Y. (1988). The midlessness of organizational behaviors. Human Relations, 41(4), 305-329.

Barley, S. R. (1986). Technology as an occasion for structuring: Evidence from observations of CT scanners and the social order of radiology departments. Administrative Science Quarterly, 31, 78-108.

Broadbent, D. (1958). Perception and communication. New York: Pergamon.

Browning, L. D., \& Henderson, S. C. (1988). One-way communication transfers in loosely coupled systems. In J. A. Anderson (Ed.), Communication Yearbook (Vol. 12, pp. 638-669). Newbury Park, CA: Sage.

Burgoon, J. K., Berger, C. R., \& Waldron, V. R. (2000). Mindfulness and interpersonal communication. Journal of Social Issues, 56(1), 105-127.

Burgoon, J. K., \& Langer, E. J. (1996). Language, fallacies, and mindlessness-mindfulness in social interaction. Communication Yearbook, 18, 105-132.

Daft, R. L., \& Lengel, R. H. (1984). Information richness: A new approach to managerial behavior and organizational design. In B. M. Staw \& L. L. Cummings (Eds.), Research in Organizational Behavior (pp. 191-233). Greenwich, CN: JAI Press.

Daft, R. L., \& Lengel, R. H. (1986). Organizational information requirements, media richness and structural design. Management Science, 32(5), 554-571.

Daft, R.L. \& Lewin, A.Y. (1990). Can organization studies begin to break out of the normal science straitjacket: An editorial essay. Organization Science, 1, 1,

Einhorn, H. J., \& Hogarth, R. M. (1986). Judging probable cause. Psychological Bulletin, 99, 1-39.

Follett, M. P. (1924). Creative experience. New York: Longmans.

Fulk, J., Steinfield, C. W., Schmitz, J., \& Power, J. G. (1987). A social information processing model of media use in organizations. Communication Research, 14(5), 529-552.

Gioia, D., \& Poole, P. P. (1984). Scripts in organizational behavior. Academy of Management Review, 9(3), 449-459.

Gioia, D. A. (1986). Symbols, scripts and sensemaking: Creating meaning in the organizational experience. In H. P. Simms \& D. A. Gioia \& a. Associates (Eds.), The Thinking Organizations (pp. 49-74). San Francisco: Jossey-Bass.

Glaser, B. G. (1978). Theoretical sensitivity: Advances in the methodology of grounded theory. Mill Valley, CA: The Sociology Press.

Glaser, B. G., \& Strauss, A. L. (1967). The discovery of grounded theory: strategies for qualitative research. Chicago: A ldine.

Langer, E. J. (1978). Rethinking the role of thought in social interaction. In W. I. J. Harvey \& R. Kidd (Eds.), New Directions in Attributional Research (Vol. 2, pp. 35-58). Hillsdale, NJ: Erlbaum.

Langer, E. J. (1989). Mindfulness. Cambridge, MA: Perseus.

Langer, E. J., \& Moldoveanu, M. (2000). The construct of mindlfulness. Journal of Social Issues, 56(1), 1-9.

Lengel, R. H., \& Daft, R. L. (1988). The selection of communication media as an executive skill. The Academy of Management Executive, 2(3), 225 - 232.

Miles, M. B., \& Huberman, A. M. (1994). Qualitative data analysis: An expanded sourcebook (2nd ed.). Thousand Oaks, CA: Sage.

Orlikowski, W. J. (2000). Using technology and constituting structures: A practice lens for studying technology in organizations. Organization Science, 11(4), 404-428.

Rice, R. E. (1993). Media appropriateness: Using social presence theory to compare traditional and new organizational media. Human Communication Research, 19(4), 451-484.

Shannon, C. E., \& Weaver, W. (1949). The mathematical theory of communication. Urbana, IL: University of Illinois Press.

Sitkin, S. B., Sutcliffe, K. M., \& Barrios-Choplin, J. R. (1992). A dual-capacity model of communication media choice in organizations. Human Communication Research, 18(4), 563 - 598.

Smircich, L., \& Stubbard, C. (1985). Strategic management in an enacted world. Academy of Management Review, 10(4), 724-736. 
Strauss, A. (1970). Discovering new theory from previous theory. In T. Shibutani (Ed.), Human Nature and Collective Theory. Englewood Cliffs, NJ: Prentice-Hall Publishing.

Sutcliffe, K. M. (2001). Organizational environments and organizational information processing. In F. M. Jablin \& L. L. Putnam (Eds.), The New Handbook of Organizational Information (pp. 197-230). Thousand Oaks, CA: Sage.

Timmerman, C. E. (2002). The moderating effect of mindlessness/mindfulness upon media richness and social influence explanations of organizational media use. Communication Monographs, 69(2), 111-131.

van den Hoonaard, W. C. (1997). Working with sensitizing concepts (Vol. 41). Thousand Oaks, CA: Sage.

Weick, K. E. (1969). The social psychology of organizing. Reading, MA: Addison-Wesley.

Weick, K. E. (1979). The social psychology of organizing (2nd ed.). Reading, MA: Addison-Wesley.

Weick, K. E. (1988). Enacted sensemaking in crisis situations. Journal of Management Studies, 25, 305-317.

Weick, K. E. (1995). Sensemaking in organizations. Thousand Oaks, CA: Sage.

Weick, K. E. (2001). Making sense of the organization. Malden, MA: Blackwell Publishers.

Wenberg, J., \& Wilmot, W. (1973). The personal communication process. New York: John Wiley and Sons.

\section{Biographies:}

Alf Steinar Sætre is an Associate Professor in the Department of Industrial Economics and Technology Management at the Norwegian University of Science and Technology in Trondheim, Norway. Alf Steinar's research focuses in innovation and ICT use in organizations, new venture financing and organizational communication. His consulting work focuses on communication in organizations and on new venture acceleration. Alf Steinar's Ph.D. is from The University of Texas at Austin; his MSc is from The Norwegian School of Econo mics and Business Administration.

Jan-Oddvar Sørnes is a Research Fellow/lecturer at Bodø Graduate School of Business at Bodø University, Norway, and a Doctoral student in the Department of Ind ustrial Economics and Technology Management at the Norwegian University of Science and Technology in Trondheim, Norway. Jan's research focus is on ICT use in organizations and e-learning. He has 10 years of experience with e-learning and ICT use in higher education. Jan teaches introductory courses in Computer Science and Information Systems. He has a Masters degree from Michigan State University, and an undergraduate degree from University of Idaho.

Keri Stephens is a doctoral student in organizational communication in the Department of Communication Studies at the University of Texas at Austin. Keri's focus is on the use of research knowledge for applied problems and has written award winning papers on the use of information/communication technologies and conducts research on a variety of organizational communication and technology issues including virtual immediacy, crisis communication, representation and identity, and collaborative innovation. She has a Masters degree from the University of Texas at Austin and graduated with an undergraduate degree from Texas A\&M University.

Larry Browning is a Professor of Organizational Communication and Director of Graduate Studies in the Department of Communication Studies at the University of Texas at Austin. Larry's research on organizations is published in a variety of communication and management journals including: Communication Monographs, Academy of Management Journal, Communication Theory, Journal of Management, Communication Studies, Communication Education, Journal of Organizational Change Management, Journal of Applied Communication Research, Electronic Journal of Communication, Handbook of Organizational Communication, and Communication Yearbook 13. His recent scholarship, published in 2000, (with Judy Shetler) is: Sematech: Saving the U.S. Semiconductor Industry. College Station, TX: Texas A \& M University Press. Larry's Ph. D is from Ohio State; his MA and BS are from Oklahoma University. 